\title{
A história dos institutos de pesquisa na Amazônia
}

\author{
PRISCILA FAULHABER
}

A

SIGNIFICAÇÃO DA FRONTEIRA amazônica dentro da política científica, no que se refere à história dos institutos nacionais de pesquisa na Amazônia, leva a focalizar a relação entre campo científico, construção do Estado nacional e intervenção regional. Tais definições, relacionadas com os conceitos de campo e estratégia são consideradas dentro de uma reflexão mais geral sobre as vinculações entre política científica e campo político.

A criação do Inpa (Instituto Nacional de Pesquisas da Amazônia), como desdobramento do processo de fundação do CNPq (Conselho Nacional de Pesquisas), em 1951, situou-se dentro de estratégias de construção do Estado Nacional no Brasil, que implicaram um processo de nacionalização, apresentando-se como uma instituição "pioneira" no sentido de tomar para si, do ponto de vista de uma política científica nacional, uma conjunção de projetos internacionais, estaduais e locais.

A fundação do CNPq esteve intrinsecamente relacionada, inicialmente, com a definição de uma política científica, sobretudo motivada pela questão nuclear, e que apenas indiretamente dizia respeito a uma política científica em relação à Amazônia. Esta região, no entanto, representava interesses estratégicos para o Estado Nacional brasileiro no sentido da incorporação de fronteiras territoriais, científicas e culturais. Despertava, igualmente, o interesse de instituições científicas internacionais, como a Unesco, com as quais o CNPq travava convênios e tratados de cooperação.

Arthur Cezar Ferreira Reis, no seu relatório de 1956, define a Amazônia como "um mundo por descobrir e identificar", "um espaço aberto à ousadia dos mais dispostos" (Ferreira Reis, 1956, p. 4). Conferiu assim à Amazônia o caráter de "fronteira científica", ou seja: unidade socioterritorial passível de incorporação, dentro de um projeto de Estado que a toma como um desafio para o conhecimento. A este caráter de fronteira científica associava-se o caráter de "fronteira internacional", uma vez que se apresentava como o denominador comum de diferentes projetos nacionais, bem como o caráter de "fronteira econômico-social" enquanto objeto de frentes de expansão, ou seja, área a ser incorporada dentro de propósitos nacionais, tais como desenvolvimento, integração e potência - esta última garantida via expressão militar do poder nacional.

Paralelamente à criação do Inpa, concebido em 1952 e instalado a partir de 1954, incorporou-se o Museu Goeldi, fundado como Museu Paraense de Etnogra- 
fia e História Natural em 1866 pelo naturalista mineiro Domingos Soares Ferreira Penna, inicialmente vinculado a uma Associação Filomática (Cunha, 1989). À institucionalização do Museu Paraense correspondeu a profissionalização dos seus quadros (Faulhaber, 2001). Já na gestão do botânico Suíço Emílio Goeldi, dentro de um projeto de Estado, análogo a outros processos na América Latina que resultaram na criação de outras figuras congêneres, encaradas como símbolos de identidade nacional, tal como a Universidade nacional da Colômbia em 1867, que nasceu como uma Universidade Nacional, Pública e do Estado, no cenário do radicalismo liberal, dentro do qual se propunha a inspeção pública e vigilância estatal da instrução pública ${ }^{1}$.

A criação do Inpa pelo $\mathrm{CNPq}$, como uma instituição pioneira, consubstanciava uma resposta da política científica do Estado Nacional no Brasil à significação da Amazônia em termos internacionais, configurada, desse modo, como uma fronteira científica. No entanto, a preexistência de uma instituição como o Museu Goeldi, como representante local da tradição científica, levou à incorporação à política de desenvolvimento, de disciplinas relacionadas às áreas de história natural e etnografia, em termos da criação de departamentos de ciências biológicas e ciências humanas dentro desse Museu, que passou a ser estruturado como um instituto de pesquisa governamental, primeiramente articulado ao $\mathrm{CNPq}$ a partir de 1983, e, desde 1999, como o Inpa, passa a integrar-se ao MCT. Tratarse-á, neste trabalho, de uma abordagem da história de tais institutos de pesquisa no que se refere à significação da Amazônia para a intervenção da política científica, à simetria entre as disciplinas e ao lugar das ciências humanas.

\section{A história das instituições e a fronteira científica}

A história das instituições científicas tem se voltado, atualmente, para o estudo de um complexo de variáveis, um tecido social que abrange múltiplas interações que compreendem redes de pesquisadores e instituições, com ênfase em descrições referentes a práticas comunicativas historicamente contingentes, como a recepção e a tradução da ciência em todo o mundo (MacLeod, 2000, p. 6). Dentro dessa ótica, verifica-se uma ruptura com a formação colonial, uma vez que os atores científicos não estão restritos a uma relação de dependência diante de um único centro colonizador determinante, mas têm margem de escolha entre diferentes alternativas disponíveis (Chambers e Gillespie, 2000, p. 223).

Nos atuais processos planetários de integração de mercados, as instituições científicas configuram-se como um tecido social que abrange múltiplas interações, as quais que compreendem redes de pesquisadores e agências públicas e privadas, com ênfase em descrições não prescritivas referentes a práticas comunicativas historicamente contingentes, recepção e tradução da ciência em todo o mundo (MacLeod, 2000, p. 6). Apesar dos processos de ruptura com a formação colonial, observa-se, no entanto, a recorrência de práticas referentes a uma continuidade do processo de colonização, bem como a emergência de discursos a ele associados, como os referentes'à superioridade da civilização ocidental sobre a 
natureza, e ao sucesso científico como fase última do processo colonizador (Osborne, 2000, p. 151).

O estudo da história das ciências coloniais mostrou que as lutas pela independência apresentavam-se articuladas a projetos científicos nacionais que criaram um discurso auto-referenciado (MacLeod, 2000, pp. 2-4). Os próprios Museus de História Natural transformaram-se em um lugar de nacionalização das culturas locais, dentro do chamado processo civilizador, no qual os povos nativos eram submetidos ao batismo científico, despojados de seus artefatos, transfigurados pela cultura do exotismo, e incluídos nas espécies a serem inventariadas. Esses Museus participavam dos processos de invenção das identidades nacionais, explorando territórios, conferindo valor a objetos colecionados e legitimidade a políticas territoriais. Celebrizou-se, por exemplo, a participação de Emílio Goeldi, diretor do Museu Paraense de Etnografia e História Natural na comissão que determinou as fronteiras entre o Brasil e a Guiana Francesa, firmando "a estampa nacional em territórios anteriormente desconhecidos", durante o apogeu da exploração da borracha (Lopes e Podgorny, 2000, p. 114). Embora não se pudesse mais propriamente falar de Império colonial, uma vez que, proclamada a República, o Brasil relacionava-se como tal com outros Estados Nacionais, dentro de um processo em curso de colonização territorial.

Destaca-se entre os antecedentes da fundação do Inpa a reinterpretação de um projeto "vindo de fora", o utópico projeto de criação do Instituto Internacional da Hiléia Amazônica (IIHA), apresentado na esteira de tentativas anteriores da política de Estado de enfrentar o desafio amazônico, tais como o Instituto Agronômico do Norte. Tais tentativas, no entanto, ainda não reuniam todas as características - científicas, econômicas, sociais - do projeto consubstanciado nos anos de 1950. Destaca-se, nesse sentido, o papel do Estado no esforço para criar "redes amazônicas" no sentido de neutralizar as defasagens históricas entre o Brasil e os países do Norte (Maio e Sá, 1997).

Os interesses de projetos específicos relacionados com o IIHA, voltados à ecologia humana e o meio ambiente amazônico, passavam por determinações sócio-históricas (Petitjean, 1992; Bertol e Petitjean, 2000), paralelamente à autonomização da antropologia, como uma disciplina das ciências humanas e sociais, tomadas como distintas das ciências naturais, ao mesmo tempo em que se formavam associações científicas congregando representantes de disciplinas específicas. Essas associações eram formadas dentro da militância profissional de pesquisadores que atuavam na formação dos campos científicos dos países nos quais realizavam suas pesquisas. Cita-se, como exemplo, Paul Rivet, ator político expressivo na formação da Sociedade de Americanistas de Paris e em contextos nacionais do Brasil e da Colômbia ${ }^{2}$, e de Alfred Métraux. Este último, em artigo do boletim da sociedade de americanistas criticou, dentro da perspectiva da antropologia clássica, o enfoque de populações não representativas da indianidade amazônica dentro do projeto do IIHA, tendo também apresentado recomenda- 
ções no sentido de que o serviço à ciência e à humanidade implicava a valorização da dignidade das populações nativas.

\section{Campo científico, construção nacional e o problema da intervenção regional}

Entende-se campo científico como lugar objetivo de um jogo onde se encontram engajados investimentos e comprometimentos simbólicos e práticos. As determinações propriamente científicas encontram-se intrincadas com as determinações sociais, uma vez que o interesse intrínseco não é dissociável do interesse extrínseco no terreno das motivações científicas (Bourdieu, 1976, p. 90). Os institutos de pesquisa na Amazônia aparecem, do ponto de vista da política científica, como unidades de intervenção regional, como lugar de territorialização de políticas concebidas a partir do campo científico, que envolvem a construção de representações sobre a natureza e a ocupação humana.

A região abrange sub-regiões, constituídas conforme agrupamentos socioculturais (índios, ribeirinhos, pretos, colonos,) ou tipologias naturais e ambientais (províncias extrativas, minerais ou agriculturáveis) que caracterizam limites intra-regionais. Locais com uma disposição similar de elementos e relações semelhantes entre si são aproximáveis uns aos outros, e lugares com relações ou elementos diferentes são agrupados separadamente (Mol e Law, 1994, p. 649). Tal confronto entre mundos sociais divergentes implica o equacionamento de problemas regionais, como expressão de debates sobre a necessidade de conservação e exploração/ aproveitamento de recursos em função de objetivos econômicos de Estado, envolvendo definição de fronteiras superpostas (Star e Griesemer, 1989, pp. 410-411); assim como ocorre no que se refere à identificação concomitante de terras indígenas, unidades de preservação ambiental e áreas de aproveitamento de recursos extrativos (pesqueiros, madeireiros etc.).

Cada autor está sempre posicionado em uma constelação de interesses que perpassam as instituições e as unidades de intervenção, ainda que referentes a um estado específico do campo científico. A distinção, formulada por Robert Merton (1973, p. 55), entre conflitos “sociais” e conflitos “intelectuais” aparece como uma estratégia por parte desse campo científico, de delimitação da sua legitimidade e de seus objetos de discussão. No entanto, tal distinção é relativa, dentro da discussão conceitual, considerando tal campo como clivado por hierarquias e intrinsecamente articulado ao campo político, observando-se no seu seio lutas por capital econômico e simbólico. Cabe, desse modo, estabelecer o estudo exaustivo das alianças e rupturas entre atores do campo político, derivadas de vinculações diferenciadas que implicam divergências de caráter circunstancial ou permanente. Os campos aparecem como que imbricados em um vasto espectro de envolvimentos, no qual as definições de prioridades se encontram determinadas por uma série de injunções econômicas e políticas. A autonomia científica será sempre relativa, no sentido da definição metodológica de um campo de intervenção, um conjunto de linhas de força em áreas de intersecção com os campos político, 
jurídico, educacional e outros. Este campo de intervenção é definido a partir da convenção de um "consenso no discenso" (Bourdieu, 1968, p. 142), que configura a unidade objetiva de um determinado campo intelectual em uma determinada época ou situação institucional.

A estrutura do campo científico é definida pelo estado da relação de forças entre agentes e instituições, protagonistas de determinado enfrentamento, ou seja, pelo contrapeso da distribuição do capital específico que comanda as estratégias e as possibilidades objetivas dos diferentes agentes e instituições, na economia das trocas que inscrevem o capital científico. A posição que cada agente singular ocupa em um momento dado do tempo na estrutura do campo científico é objetivada nas instituições e incorporada às disposições do conjunto de estratégias abertas a este agente a partir de tal posição. As transformações da estrutura do campo são o produto de estratégias de conservação ou subversão que encontram o princípio de sua orientação e de sua eficácia das propriedades da posição ocupada na estrutura por aqueles que acionam as referidas transformações.

A luta pela legitimidade científica depende da estrutura de distribuição do capital de reconhecimento entre os participantes dessa luta. Nela se distinguem os agentes e as instituições que dispõem de capital acumulado, e as instituições e os agentes iniciados, que possuem um capital importante, à medida que ocupam posições de risco, pois sua permanência no campo é questionada, e devem mobilizar todos os recursos a que têm acesso para garantir o seu lugar nesse campo. Instituições em lugares considerados "periféricos", tal como as unidades de investigação da Amazônia, são consideradas estratégicas pela política científica, de modo que instituições e cientistas já consolidados, mas que disputam sua permanência no campo científico, consideram-nas centrais no estabelecimento de projetos e convênios. As disputas próprias ao estabelecimento das controvérsias intelectuais não consistem privilégio de um lugar social ou outro.

O exame da "ciência em ação" mostra como ela opera dentro de uma rede de comprometimentos que compõem a sua traduzibilidade dentro de um princípio de simetria na relação entre disciplinas científicas, tal como formulado por Bruno Latour em suas Regras de método (1989, p. 26). Como a ação da pesquisa implica a construção social de fatos científicos, a regulação das controvérsias nas ciências biológicas torna relevantes representações da natureza. A criação de unidades de conservação não são a causa, mas o efeito da prática da ciência, de determinado diagnóstico a partir do qual são formulados problemas de análise e intervenção. Não é o estado da natureza "em si" que produz a controvérsia científica, mas a construção social dos problemas. Do mesmo modo, para as ciências humanas e sociais, o "estado de sociedade" tampouco explica a resolução de uma controvérsia (Latour, 1989, p. 426). São os problemas de investigação que levam à construção de determinados fatos enquanto sujeitos e objetos de conhecimento. 


\section{A significação da Amazônia e a simetria entre as disciplinas científicas}

Em uma tradução das abordagens de diferentes disciplinas, seus enfoques seriam simétricos em relação às suas explicações, visto que a "ciência em ação" da natureza tem por resultado "estados das coisas" em permanente transformação, assim como a "ciência em ação da sociedade" tem por conseqüência "estados do coletivo" em transformação. A tradução não parte de uma dicotomia entre diferentes esferas de conhecimento, mas baseia-se em uma "realimentação" das disciplinas. A regulação das controvérsias se estabelece dentro de redes sociais e institucionais de estratégias entre "fortes" e "fracos". Nesse campo de envolvimentos, observam-se relações de simetria e assimetria. Identificam-se movimentos em que os pontos fracos se tornam fortes e os fortes se tornam fracos, em inversões que levam a desencontros e reencontros, no qual políticas científicas envolvidas qualificam a fecundidade das experiências coletivas (Latour, 1999, p. 266).

Ao se falar em simetria entre as disciplinas rompe-se com o princípio positivista que postula uma hierarquia entre as ciências exatas, biológicas e humanas, dentro de uma ordenação que colocou no topo a física, e, na base, a sociologia e a política (Smith, Best e Stubbs, 2000, p. 73). Simetria, contudo, não é o mesmo que imparcialidade, baseada em uma suposta "neutralidade" (Pels, 1996, p. 277). Tal neutralidade não é observável sequer nas chamadas ciências exatas, pois os problemas com os quais estas trabalham são construídos em toda uma dinâmica social. A participação de Cesar Lattes na "descoberta do Meson" na radiação cósmica, por exemplo, se deu dentro de todo um processo social e político que envolvia a questão nuclear e os alinhamentos e as competições entre grupos de pesquisa de países do Norte e do Sul, processo este que teve implicações no sentido da fundação do CBPF (Centro Brasileiro de Pesquisas Físicas) e do CNPq (Andrade, 1999, p. 147). Quando Cesar Lattes se fixou no Brasil e não em prestigiados centros de pesquisa da Europa e dos Estados Unidos, era motivado por vínculos pessoais com valores nacionais, posicionados em uma rede de relações internacionais.

Quando se focaliza as controvérsias relacionadas com a fundação do CNPq no que se refere à intervenção de grupos profissionais, verifica-se que esta fundação esteve ligada inicialmente com o empenho de um grupo de físicos na constituição de um campo científico e na profissionalização de suas pesquisas ${ }^{3}$.

A Fundação da SBPC, dois anos antes, por um grupo de biólogos da Universidade de São Paulo (USP), já evidenciara a relevância das ciências biomédicas. $\mathrm{O}$ prestígio do $\mathrm{CNPq}$, no entanto, foi, mais propriamente, associado à participação de um grupo de físicos em pesquisas com a energia nuclear os quais, apoiados pelo Ministro João Alberto Lins e Barros, fundaram o Centro Brasileiro de Pesquisas Físicas, em 1949. O interesse nacional e internacional despertado por pesquisas geológicas, botânicas e zoológicas na região amazônica apresentava 
desafios para a política científica e para a construção do Estado Nacional, tornando-se determinante para a criação do Inpa, instalado em 1954. Essa rede de implicações levou à constatação de que não se podia deixar de incluir as coleções científicas do Museu Goeldi, cujo acervo se destacava também nos domínios geológico, etnográfico e arqueológico. Inicialmente, o CNPq só financiou indiretamente as pesquisas em ciências humanas, com o apoio a pesquisas em sambaquis por Luís de Castro Faria, com a colaboração etnobotânica com o estudo do curare, de acordo com informações de Roberto Cardoso de Oliveira (Faulhaber, 2001), que recebeu uma bolsa do CNPq em 1958, como pesquisador do Museu Nacional.

No que se refere à Amazônia, a fundação do Inpa implicava uma ruptura com uma visão dos Museus como instituições arcaicas. O Estado Nacional precisava impor sua própria marca para romper com o passado colonial e impor sua presença no cenário científico mundial. O Inpa, criado com a marca dessa modernidade, precisou incorporar o conhecimento acumulado nas coleções científicas do Museu Goeldi. Desde o seu início, fazia-se história natural no Museu Goeldi, e a pesquisa etnográfica com índios lá sempre esteve presente, seja dentro da tradição humanista, associada a estudos históricos e geográficos, seja como disciplina integradaà história natural.

Os primeiros diretores do Inpa, a par de serem ilustrados em história e humanidades estavam diretamente vinculados às políticas de desenvolvimento regional e nacional, como Arthur Cezar Ferreira Reis (1956-1958), e às políticas de medicina tropical, como Djalma Batista (1959-1968). A breve existência, de 1944 a 1949, de um grupo de intelectuais locais em torno do Instituto de Etnografia e Sociologia do Amazonas (Iesa), criado dentro de um movimento "de defesa do patrimônio etnográfico e etnológico da região" centralizado por Nunes Pereira e Geraldo Pinheiro (Costa, 2000), indica que não se vivia em absoluto vazio cultural na província amazonense. Acolheu-se a idéia da instalação Inpa como uma possibilidade de o Estado do Amazonas redimir-se do grande isolamento e da dificuldade de acesso a instrumentos e recursos para a pesquisa científica. A contratação do autodidata Mário Ypiranga Monteiro como bolsista para realizar pesquisas relacionadas à antropologia, os contatos do escritor Nunes Pereira e as visitas de Noel Nutels a Manaus não se mostraram suficientes, no entanto, para um criar um clima favorável à atração de Eduardo Galvão, cuja atuação em Belém imprimiu uma marca na antropologia regional e nacional.

No MPEG, a pesquisa relacionada com atividades museológicas implicou que os pesquisadores em ciências biológicas vinculados a esta instituição trabalhassem predominantemente com história natural e taxonomia, dentro do paradigma da evolução das espécies, dentro de todo um campo de relações entre museus e instituições nacionais e internacionais, as quais, além de um interesse científico, estavam relacionadas com interesses econômicos e políticos, entre os quais se destaca o conhecimento geológico para a exploração mineral. 
O reconhecimento da contribuição substantiva de pesquisas etnográficas pelo campo científico antropológico internacional se fez notar no Museu Goeldi a partir de Curt Nimuendaju (2000, p. 321 ), que publicou em veículos antropológicos reconhecidos, a partir dos anos de 1920. Nesse período registrou-se, em Belém, a existência do Instituto de Antropologia do Pará, fundando com o objetivo de dar ênfase aos estudos regionais e reanimar as atividades do Museu Goeldi (Pereira, 1946). Considerando-se a formação do campo científico antropológico desde o início do século XX, Curt Nimuendaju destaca-se como um coletor de peças etnográficas consideradas como "mercadoria e meio de troca dentro da restrita economia política da pesquisa antropológica” (Stocking, 1985, p. 113). Porém, o reconhecimento editorial de sua produção etnológica (Nimuendaju, 1952), bem como sua comunicação com nomes como Lowie e Steward, entre outros, leva a qualificar seu trabalho como obra etnográfica (Cardoso de Oliveira, 1986) significativa na história da antropologia social, que se diferenciava como um campo específico de conhecimento academicamente orientado, independente da história natural (Stocking, 1985, pp. 140-142).

As informações sobre a trajetória de Eduardo Galvão (1921-1976) fornecem indicações para a abordagem da formação da antropologia social no Brasil, bem como para reflexões sobre as transformações na universidade e suas relações com a institucionalização da pesquisa científica em ciências humanas, com a criação da pós-graduação. Aluno de Heloísa Alberto Torres, e estagiário do Museu Nacional, acompanhou a expedição de Charles Wagley aos Tapirapé, criando vínculos pessoais e profissionais que dirigiram sua trajetória para tornar-se o primeiro brasileiro PhD em antropologia, com a obtenção deste título na Universidade de Columbia em Nova York (1947-1949) conforme consta em seu currículo.

Eduardo Galvão trabalhou no Serviço de Proteção aos Índios, a partir 1952, como chefe da Seção de Orientação e Assistência. Integrou-se ao Museu Goeldi em 1955, quando foi motivado a reescrever, em português, sua tese em uma linguagem acessível ao público (Galvão, 1976). Associa-se seu estabelecimento em Belém à formação de um campo de pesquisa em antropologia, lingüística e arqueologia no Museu Goeldi, que anteriormente era caracterizado pela iniciativas individuais, ainda que ligadas ao campo antropológico em formação, como a trajetória de Curt Nimuendaju. Com a presença de Galvão, o Museu recebia visitas de pesquisadores de sua rede de relações cujas pesquisas lá encontravam um referencial intelectual e um certo apoio logístico, sendo uma porta de entrada para quem quisesse fazer pesquisa antropológica na Amazônia, pois, como instituição ligada ao Inpa e CNPq, dispunha de recursos para seus pesquisadores realizarem trabalhos de campo, uma vez que fora deste instituto seria preciso integrar-se a outras áreas de pesquisa, como a botânica. Galvão contou com a participação efetiva de profissionais formados nos cursos da Universidade Nacional de Filosofia, mas que não se fixaram definitivamente na região, como Carlos Moreira, Klaas Wortmann e Roberto las Casas, que fizeram pesquisas antropológicas na Amazônia antes mesmo de se vincular ao MPEG, como bolsistas do 
Curso de Aperfeiçoamento em Antropologia Cultural, financiado pela Capes. A área de pesquisa destes dois últimos - que estudavam posseiros em terras nas margens da rodovia transamazônica - além disso, não coincidia com as pesquisas tradicionais em etnologia e voltava-se para questionamentos sociais que foram mal vistos por setores conservadores. Em 1963, Galvão afastou-se do MPEG para criar o Departamento de Antropologia da Universidade de Brasília, a convite de Darcy Ribeiro, para de lá retornar a Belém após medidas repressivas impostas pelo regime militar ${ }^{4}$.

Voltando ao Museu Goeldi criou, em 1968, um curso de especialização visando a formar estudantes egressos da Universidade Federal do Pará para aproveitar os recursos humanos regionais que, em princípio, seriam mais facilmente adaptáveis à vida local. Este curso constituía-se em um momento mais geral de dinamização da universidade, ainda no governo militar, quando - após o "parecer para definição dos cursos de pós-graduação (parecer n⿳0 953/65)" relatado por Newton Sucupira e formulado segundo o modelo americano - visava a regulamentar o credenciamento dos cursos de pós-graduação no Brasil.

A Reforma Universitária de 1968 representou, de certa forma, continuidade com o projeto universitário que visava a conjugar pesquisa e ensino dentro da cultura científica nacional, conforme idealizado por Anísio Teixeira (2000, p. 100). De acordo com o próprio Teixeira, a Reforma propunha uma renovação da universidade, e o desmonte do sistema de catedráticos (Teixeira, 2000, pp. 261-182). Mas implantava-se em um momento completamente diferente do anterior, o que propiciou uma maior participação dos professores, dentro de um sistema ainda hierárquico de departamentos vinculados a institutos de pesquisa.

No governo militar, entretanto, determinou-se o estreitamento das relações entre pesquisa e pós-graduação, na qual o CNPq cumpriu um papel de destaque como agência responsável pelo desenvolvimento científico e tecnológico, estando vinculado às políticas nacionais de planejamento e desenvolvimento econômico e ainda associado ao conceito de defesa nacional. Consolidaram-se assim, as instâncias de articulação entre pesquisa científica e ensino de pós-graduação, dando continuidade a estratégias de integração ensejadas nos anos de 1950, com as primeiras formulações dos artífices da Capes e do CNPq. O sistema de pós-graduação incluiria um leque diversificado de áreas de conhecimento, entre as quais as ciências sociais que, no decorrer do tempo, constituiriam suas instituições representativas. A partir de seu reconhecimento como um campo específico de conhecimento que implica a afirmação de sua identidade científica, nota-se sua nítida expansão em termos de atendimento às demandas por fomento, sobretudo com dinamização do setor de ciências sociais, implantado no $\mathrm{CNPq}$ desde a sua reformulação, em 1964 (Forjaz, 1988, p. 28), e fortalecido com a transformação do órgão em Conselho Nacional de Desenvolvimento Científico e Tecnológico, por meio da lei no 6.129 de $1^{\circ}$ de novembro de 1974. Entre as principais transformações, destaca-se a criação da Superintendência de Desenvolvimento Científico, organizada em coordenações setoriais de acordo com as 
áreas de desenvolvimento, e a substituição do Conselho Deliberativo pelo Conselho Científico e Tecnológico ${ }^{5}$. Apesar dessa última transformação, não obstante, observou-se a continuidade de princípios no tocante a uma concepção acadêmica de conhecimento científico que contribuía para a criação, em 1973, dos comitês assessores, os quais passaram a ouvir as associações científicas e entidades representativas das diferentes áreas de conhecimento (Forjaz, 1988, p. 31).

A valorização, pelo governo militar, do desenvolvimento científico e tecnológico, com o objetivo de desenvolver áreas estratégicas, como energia nuclear, pesquisas espaciais, petróleo e informática, indiretamente, impulsionou a pesquisa científica e as ciências sociais, sobretudo a partir de meados dos anos de 1970, no processo conhecido como "distensão democrática", passada a época negra da repressão generalizada às iniciativas consideradas subversivas. Observou-se, a partir daí, uma nítida expansão das ciências humanas, ainda que os montantes de recursos a elas destinados continuem mais baixos comparativamente às ciências exatas e biológicas. Ademais, os programas de pós-graduação em ciências sociais que surgiram desde 1968 também passaram a ser cada vez mais apoiados (Miceli, 1995). Entre esses programas, destaca-se a criação e a implementação do Programa de Pesquisa e Pós-Graduação em Antropologia Social do Museu Nacional, em 1970, que inicialmente não contou com o fomento da Capes ou do CNPq, mas da Fundação Ford. Viabilizado dentro de um convênio com a Universidade de Harvard, a partir do Projeto Comparativo para o Desenvolvimento Regional, elaborado por Roberto Cardoso de Oliveira, o Programa de Pesquisa e Pós-Graduação em Antropologia Social do Museu Nacional obteve como resultado a dissertação de Otávio Velho (1972), em áreas da Amazônia legal. A partir de 1974, com o início da distensão política, observouse um crescente incremento da avaliação positiva das demandas dentro das ciências humanas e sociais como área de conhecimento do CNPq, que continua a verificar-se até os dias de hoje (Abreu, 2001). Surgiram questões referentes à especificidade, à heterogeneidade e à especialização deste campo disciplinar, bem como à sua aplicação prática no sentido, por exemplo, da promoção de ajustes sociais e da criação de uma nova visão da difusão científica, na qual as demandas sociais e os imperativos éticos não se dissociam (Ribeiro, 2000). Essa perspectiva, face às ciências humanas e sociais, também passou a nortear a formulação de metas científicas e tecnológicas para a região amazônica. em torno de temas como a biodiversidade, o desenvolvimento sustentável ou a violência no campo.

A distensão política propiciou uma maior descentralização administrativa e foi acompanhada da informatização e do incentivo à formação de departamentos dentro dos Institutos de Pesquisa, sobretudo na gestão de José Dion de Melo Teles (1975 a 1979). O apagar das luzes do período militar, na primeira metade dos anos de 1980, representou um movimento de regionalização, personalizado pela figura de Lynaldo Cavalcante de Albuquerque, que fora reitor da Universidade de Campina Grande, na Paraíba e defendia a regionalização da ciência. Com a atuação do economista Manuel Marcos Formiga como superintendente 
de Desenvolvimento Científico, prestigiaram-se as associações científicas e os comitês de humanidades, criando o Museu de Astronomia e Ciências Afins, com uma área de história da ciência. Neste momento, fortaleceu-se o Inpa, e na gestão de José Seixas Lourenço o Museu Goeldi dele se desvinculou, constituindo um Conselho Técnico e Científico autônomo. Até então, as questões técnicas e científicas deste instituto eram decididas no CTC do Inpa, com a presença de representantes científicos do MPEG, como a antropóloga Adélia Rodrigues e o botânico Paulo Cavalcante. Diretamente vinculado ao CNPq, a partir de 1983, o Museu Goeldi, a partir das gestões de José Seixas Lourenço e Guilherme De La Penha, consolidou seus departamentos de Ciências Humanas, Botânica, Zoologia e Ciências da Terra, quando houve um grande número de contratações, sobretudo de pesquisadores integrados à instituição como bolsistas de desenvolvimento regional, muitos dos quais ingressaram e concluíram seus doutorados já como funcionários do CNPq. Os projetos departamentais se fortaleceram com o estabelecimento de programas de cooperação científica internacional, como o Programa de Pesquisa sobre Ocupação Humana da Amazônia, vinculado ao Convênio $\mathrm{CNPq} /$ Orstom (atualmente IRD), e dentro do qual se realizaram importantes trabalhos de pesquisa no MPEG e no Inpa. Outro programa relevante para o incentivo tanto da infra-estrutura quanto de atividades de atualização científica e coleções científicas das duas instituições é o PPG-7 (Egler, 2001).

\section{Construção regional, simetria e democratização científica}

A construção da região como objeto de análise e de intervenção a políticas nacionais e internacionais insere-se, como exposto acima, no equacionamento da problemática sobre conhecimento e fronteira. A fixação de um lugar para a prática científica consiste em uma estratégia na delimitação de problemas, de métodos e de teorias consideradas cientificamente pertinentes em um complexo de interesses internacionais, nacionais e estaduais, direcionados de acordo com determinações econômicas e políticas. As reivindicações de legitimidade sustentam-se na força relativa dos grupos cujos interesses elas exprimem: está em jogo a própria definição dos critérios de julgamento, de ética e de responsabilidade, bem como dos princípios de hierarquização, de modo que todos estão, de certo modo, envolvidos em algum campo de interesse, que dirige seus julgamentos.

A significação da Amazônia para a política científica faz com que a pesquisa nesta região apareça como uma fronteira científica, ou seja, como um lugar para a intervenção regional que envolve uma ampla gama de problemas, entre os quais os aspectos sociais e tecnológicos. A formulação dessas problemáticas, no entanto, depende de uma democratização científica, no sentido da formulação de relações não hierárquicas entre as disciplinas e entre as instituições científicas, dentro de uma simetria entre os problemas colocados pelos diferentes campos de conhecimento. Tal democratização, no entanto, não representa uma harmonia, implicando mesmo o acirramento de disputas por recursos e representações, nas quais a questão regional apresenta-se como preponderante. 


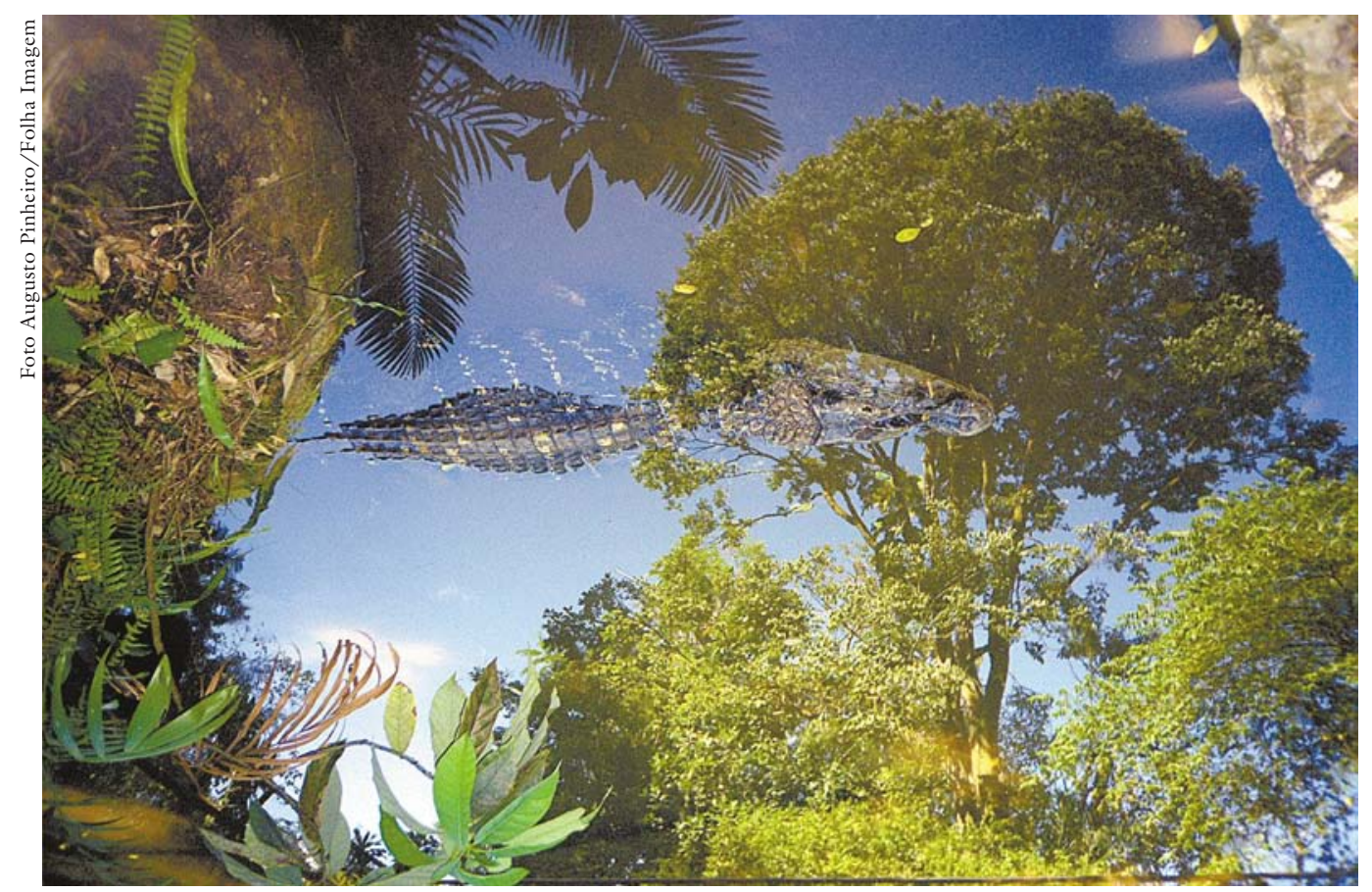

Lago do parque zoobotânico do Museu Paraense Emílio Goeldi, em Belém (PA)

No âmbito nacional, verifica-se, a partir dos anos de 1960, um crescente incremento das ciências sociais, ainda que proporcionalmente, os recursos a elas destinados tenham se mantido menores do que aqueles voltados a determinados setores das pesquisas em outros campos, tal como ocorre com a área biomédica ou tecnológica. O crescente interesse social verifica-se dentro de um processo de alinhamento com os grupos dirigentes no que se refere à constituição de elites intelectuais capacitadas para ocupar cargos de direção da política científica e tecnológica, à institucionalização da pós-graduação e no sentido de articulação entre universidade e pesquisa.

Se em momentos de arbítrio certos setores sociais qualificaram equivocadamente disciplinas das ciências sociais como "perigosas", hoje se considera sua relevância não apenas em termos de difusão científica, mas, sobretudo, para consolidar a eficácia dos programas científicos e tecnológicos e as políticas públicas, notadamente no que se refere a fornecer e a refinar instrumentos para lidar com os problemas e as transformações sociais, tornando-se relevante a questão da "aplicação" científica. Especificamente no tocante às unidades de pesquisa na Amazônia, as ciências humanas e sociais são consideradas, dentro desse quadro, como tão relevantes quanto as disciplinas biológicas ou tecnológicas - seja em termos do ensino universitário graduado e pós-graduado, seja para o público em geral - para a compreensão de problemas referentes à ocupação socioterritorial e aos recursos naturais da Amazônia, sobretudo quando se trata de considerar a contribuição dos conhecimentos nativos. 
1 Suas raízes encontram-se na Expedição Corográfica dirigida pelo geógrafo Augustin Codazzi (1850-1859), organizada com o objetivo de expansão e construção nacional. Integrada em 1950, essa Comissão teve papel fundador para a ciência nacional no país. Manuel Ancízar, um dos primeiros expedicionários, liderou o processo de fundação da Universidade nacional, em 1867, e foi o seu primeiro Reitor (segundo informações pessoais do geógrafo Camilo Domínguez, em entrevista de 22/11/1999) (Faulhaber, 2000).

2 Sobre as vinculações de Paul Rivet em termos da formação do campo antropológico em suas ramificações no Brasil e na Colômbia, consultar também Pineda Camacho, 1996 e Faulhaber, 1996.

3 A significação da atuação de grupos profissionais para a consolidação de um lugar para a ciência no projeto nacional foi apontada por Schwartzman, 2001.

4 A UnB, criada em 1961, formalizava uma concepção de universidade que definia um lugar para a Ciência, numa organização universitária, baseada no modelo americano, que previa institutos centrais de pesquisa e departamentos de ensino (Forjaz, 1988, p. 3). Apesar do radicalismo político que marcou a época, contudo, persistia um espírito autoritário e centralizador, baseada no antigo sistema de catedráticos, ou "notáveis". Galvão, convidado a cumprir este papel, não se encaixava no modelo, tanto por sua própria índole irreverente e afável, como por sua formação, dentro do sistema universitário americano, mais aberto que o brasileiro. Defendia, como uma alternativa para as pesquisas, o paradigma da mudança sociocultural relacionada com processos regionais e nacionais mais amplos que o encapsulamento comunitário. Com a crise da Universidade de Brasília, no segundo semestre de 1964 Galvão viajou para o Xingu, retornando depois a Belém.

$5 \mathrm{Na}$ Nova República, voltou-se à estrutura do Conselho Deliberativo, com a participação de representantes de associações científicas, já em um $\mathrm{CNPq}$ vinculado à estrutura ministerial propriamente dirigida em termos de uma política científica e tecnológica, com a criação do MCT, com o Ministro Renano Archer.

\section{Bibliografia}

ABREU, Alice Rangel de Paiva. "Ciências humanas e sociais no século do conhecimento. Diretrizes estratégicas para a próxima década”, em FAULHABER, Priscila e TOLEDO, Peter Mann (eds.). Conbecimento e fronteira. História da ciência na Amazônia. Brasília/ Belém, Paralelo 15/ Museu Goeldi, 2001, pp. 343-350.

ANDRADE, Ana Maria Ribeiro de. "A arena dos embates: O CNPq”, em Físicos, mésons e política. A dinámica da ciência na sociedade. Rio de Janeiro, Hucitec/ Mast/CNPq, 1999, pp. 107-172.

BOURDIEU, Pierre. "Campo intelectual e projeto criador", em POULLON, Jean et al. (orgs.). Problemas do estruturalismo. Rio de Janeiro, Zahar, 1976, pp. 105-146.

. "Le champ scientifique". Actes de la recherche en sciences sociales. Paris, CNRS, n. 2-3, jun. 1968, pp. 88-104. 
CAMACHO, Roberto. "Paul Rivet e o americanismo". Texto y Contexto. Bogotá, Universidad de los Andes, n. 5, 1985, pp. 7-20.

CHAMBERS, David W e GILLESPIE, Richard. "Locality in the History of Science". Osiris. 2a série, vol 15: Nature and Empire: Science and Colonial Enterprise, 2000, pp. 221-239.

COSTA, Selda Valle da. "O saber na selva. O Instituto de Etnologia e Sociologia do Amazonas". Revista Folhas Soltas. Manaus, Neps/ DCIS/ Universidade do Amazonas, nov. 2000, pp. 39-46.

CUNHA, Oswaldo R. Talento e atitude. Estudos biográficos do MPEG. Belém, CNPq/ MPEG, 1989.

EGLER, Paulo. "Capacitação para pesquisa e desenvolvimento em ciência, tecnologia e inovação na Amazônia”, em FAULHABER, Priscila e TOLEDO, Peter Mann (eds.). Conbecimento e fronteira. História da ciência na Amazônia. Brasília/ Belém, Paralelo 15/ Museu Goeldi, 2001, pp. 307-341.

FAULHABER, Priscila. Etnografia da antropologia sobre a fronteira amazônica (Brasil e Colômbia). Relatório de pesquisa. Belém, Museu Goeldi, 2000, digit.

. "Introdução". “O CNPq e a história dos institutos da Amazônia”. "Memória social e trajetória institucional", em FAULHABER, Priscila e TOLEDO, Peter Mann (eds.). Conbecimento e fronteira. História da ciência na Amazônia. Brasília/ Belém, Paralelo 15/ Museu Goeldi, 2001, pp. 11-31 e 351-366.

FÁVERO, Maria de Lourdes de A. Universidade do Brasil. Das origens à construção. Rio de Janeiro, UFRJ/ Comped/ MEC/Inep, 2000.

FORJAZ, Maria Cecília S. "Cientistas e militares no desenvolvimento do CNPq (19501985 )". Série História das Ciências Sociais n. 4. São Paulo, Idesp, 1988, pré-print.

GALVÃO, Eduardo. Santos e visagens. São Paulo, CEN, 1976.

LAMOUROUX, Christian. "Qualification des hommes et procédures adminstratives”. Actes de la Recherche en Sciences Sociales. vol. 133, jun. 2000, pp. 26-31.

LATOUR, Bruno. La Science en action. Paris, La Découverte, 1989.

Politiques de la Nature. Comment faire entrer les sciences en démocratie. Paris, La Découverte, 1999.

LOPES, Margaret e PODGORNY, Irina. "The Shaping of Latin American Museums of Natural History". Osiris. 2a série, vol. 15: Nature and Empire: Science and Colonial Enterprise, 2000, pp. 108-118.

MAC LEOD, Roy. "Introduction”. Osiris. 2ª série, vol. 15: Nature and Empire: Science and Colonial Enterprise, 2000, pp. 1-13.

MAIO, Marcos Chor e SÁ, Magali Romero. "Ciência na periferia: a Unesco, a proposta de criação do Instituto Internacional da Hiléia Amazônica e as origens do Inpa”. História Ciências Saxde. Manguinhos. Rio de Janeiro, Casa de Oswaldo Cruz, 1997, pp. 975-1019.

MERTON, Robert. The Sociology of Science. Chicago/London, The University of Chicago Press, 1973.

MICELI, Sérgio. “O cenário institucional das Ciências Sociais no Brasil”. História das Ciências Sociais no Brasil. vol. 2. São Paulo, Idesp/ Fapesp, pp. 26-106. 
MOL, Anne Marie e LAW, John. "Regions, Networks and Fluids: Anaemia and Social Topology". Social Studies of Science. London, Thousands Oaks and New Delhi, vol. 24, 1994, pp. 641-671.

NIMUENDAJU, Curt. "The Tukuna". University of California Publications in American Archaeology and Ethnology. vol. 45, Berkeley/ Los Angeles, 1952, pp. 1209

Cartas do sertão. De Curt Nimuendajo para Carlos Estevão. Lisboa, Museu Nacional de Etnologia/ Assírio \& Alvim, 2000.

OLIVEIRA, Roberto Cardoso de. "O que é isto que chamamos antropologia brasileira? Anuário Antropológico 85. Brasília, Tempo Brasileiro, 1986, pp. 7 -246.

OSBORNE, Michael A. "Aclimatizing the World”. Osiris. 2 ${ }^{\text {a }}$ série, vol. 15: Nature and Empire: Science and Colonial Enterprise, 2000, pp. 135-150.

PELS, Dick. "The Politics of Symmetry". Social Studies of Science. London, Thousand Oaks, CA and New Delly, vol. 26, 1996, pp. 277-304.

PEREIRA, Nunes. Curt Nimuendaju. Aspectos de uma vida e uma obra. Belém, Oficinas Gráficas, 1946.

PETITJEAN, Patrick. "Sciences et empires: um thème prometteur, des enjeux cruciaux, em PETITJEAN, Patrick et al. (eds.). Sciences et empires. Nethertlands, Kluwer Academic Publishers, 1992.

PETITJEAN, Patrick e BERTOL, Heloisa M. “A redescoberta da Amazônia num projeto da Unesco: O Instituto Internacional da Hiléia Amazônica”. Revista de Estudos Históricos-Descobrimentos. Rio de Janeiro, ano 14, n. 26, 2000, pp 265-292.

REIS, Arthur Cezar Ferreira. “O Instituto Nacional de Pesquisas da Amazônia. Origens, objetivos, funcionamento. Sua contribuição para o desenvolvimento científico da Amazônia”. Publicações Avulsas n 7. Manaus, Inpa, 1956.

RIBEIRO, Renato Janine. Documento de síntese para a reunião temática: ciências humanas. Projeto documentos e diretrizes para ciência, tecnologia e inovação (Decti). Brasília, Ministério da Ciência e Tecnologia, 2000.

SCHWARTZMAN, Simon. Um espaço para a ciência. A formação da comunidade científica no Brasil. Brasília, Ministério da Ciência e Tecnologia/ Centro de Estudos Estratégicos, 2001.

SMITH, Laurence D.; BEST, Lisa A. e STUBBS, D. Alan. "Scientific Graphs and the Hierarchy of Sciences: A Latourian Survey of Inscription Practices". Social Studies of Science. London, Newbury Park and New Delhi, 30/1, 2000, pp. 73-94.

STAR, Susan L. e GRIESEMER, James R. “Institutional Ecology, 'Translations' and Boundaries Objects: Amateurs and Professionals in Berkeley's Museum of Vertabrate Zoology, 1907-39". Social Studies of Science. London, Newbury Park and New Delhi, vol. 19, 1989, pp. 387-420.

STOCKING, George W. "Philanthropoids and Vanishing Cultures. Rockefeller Funding and the End Of the Museum Era in Anglo-American Anthropology". Objects and Others. Essays on Museums and Material Culture, 1985, pp. 112-146.

TEIXEIRA, Anísio. Educação e universidade. Rio de Janeiro, Inep/ UFRJ, 2000.

VELHO, Otávio. Frentes de expansão e estrutura agrária. Rio de Janeiro, Zahar, 1972. 
RESUMO - A REFLEX̃̃o sobre a história dos institutos científicos na Amazônia conduz ao problema da fronteira científica, considerando a significação da Amazônia para a gestão do conhecimento científico nacional. Trata-se, aqui, de focalizar as relações entre campo científico, intervenção e construção regional. Coloca-se em questão o lugar das ciências humanas e sociais dentro de uma simetria entre as disciplinas científicas.

Palavras-chave: Institutos científicos; fronteira científica; construção regional; lugar social; relações de simetria.

ABSTRACT - WHEN WE reflect on the history of the scientific amazonian institutes leads us to the problem of the scientific frontier and the meaning of the Amazon within the scientific policy. This paper focuses on the relationship between the scientific field and intervention and regional construction. The place of human and social sciences is thought to lie within the symmetry of scientific disciplines.

Key-words: Scientific institutes; scientific frontier; regional construction; social place; relations of symmetry.

Priscila Faulhaber é pesquisadora titular do Museu Goeldi/ MCT; bolsista do CNPq e docente da UFPA. Atualmente é pesquisadora visitante no Mast/RJ e ministra curso no Programa de Pós Graduação em Antropologia na UFF/RJ. @ - priscila@ism.com.br Texto recebido em 1을 $2 / 2005$ e aceito em 18/4/2005. 